\title{
Characterization of Root Diameter-Water Stress Behaviour in Epiphytes using Dendrometer
}

\author{
Mohd Khairi Nordin, Nooritawati Md Tahir, Ahmad Ihsan Mohd Yassin, and Megat Syahirul Amin \\ Megat Ali
}

\begin{abstract}
Water management and irrigation systems are vital to precision agriculture. Understanding of plant behaviour is critical for future deployment of such systems. This paper elaborates on the characterization of root diameter changes in commercial epiphytes under water stress condition. Two Vanda hybrids have been used in this study. Initially, consistency and linearity tests are performed on the dendrometers. The devices are then fixed to the root of the epiphytes. Subsequently, changes in root diameters, along with the surrounding temperature and humidity is then recorded by data loggers over a duration of two weeks, at every 15-minutes interval. The time-series data for root diameter, temperature, and humidity are analyzed. Changes to root diameter are well-captured, and the data plots have provided useful information related to the water status in roots. Parameters such as daily root shrinkage rate, maximum root minimum, and daily plots can be extracted from the recorded data. The information is useful for monitoring the quality of plant growth against changes in their needs for water.
\end{abstract}

Index Terms-Dendrometer, epiphyte, linearity test, root diameter, water stress.

\section{INTRODUCTION}

$\mathrm{P}$ RECISION agriculture requires engineering systems that are capable of supplying plants with the exact amount of resources required for optimum growth condition throughout its lifetime [1]. However, this would require extensive studies for each target plant groups, and understanding the unique factors that influences these growth behavior is the key prior to any system deployment [2]. Over the past decade, several key parameters have been studied to optimize farm resources without compromising on the crop yield. These include nutrient monitoring [3], disease management [4], harvesting technology [5], sustainable quality seedling [6], quality of plant growth [7], and water management systems [8]. To date, these areas are still being actively researched due to the impact it has on the community.

This manuscript is submitted on 3th January 2021 and accepted on 11th March 2021. This work is financially supported in part by Universiti Teknologi MARA through the MyRA 2020 Research Grant (600-RMC/MYRA 5/3/LESTARI (099/2020)).

Mohd Khairi Nordin, Nooritawati Md Tahir, Ahmad Ihsan Mohd Yassin and Megat Syahirul Amin Megat Ali are with Faculty of Electrical Engineering, Universiti Teknologi MARA, 40450 Shah Alam, Selangor, Malaysia (e-mail: mkhai974@uitm.edu.my,noori245@uitm.edu.my, ihsan.yassin@gmail.com \& megatsyahirul@uitm.edu.my).

1985-5389/C 2021 The Authors. Published by UiTM Press. This is an open access article under the CC BY-NC-ND license (http://creativecommons.org/ licenses/by-nc-nd/4.0/).
Water management is an important element in any farming activities. This is evident through the erection of irrigation channels which regularly supplies water to plants. A reliable irrigation system is therefore critical to ensure steady and profitable crop production [9]. Traditionally, farmers would water their plants using manual methods. However, the scenario is different in the larger commercial farms. The practice has been upgraded to automated irrigation systems which automatically supply water based on fixed timing schedule. In the United States, deployment of such systems has started way back in the 1990s due to the increasing demand in precision agriculture practices.

Water status in plants can be analyzed through physical measurements from the roots [10], leaves [11], and stem [12]. Meanwhile, indirect measurements methods can be derived from reflectance [13], canopy temperature [14], ultrasound [15], soil moisture [16], microwave [17], infrared [18], and remote sensing [19] techniques. Water uptake through the root is a critical process in the soil-plant-atmosphere continuum. It is not only used for plant development, but shapes microbial community, and bringing physical and biochemical changes to the soil [20]. Water status in roots have been studied from various aspects such as patterning mechanism based on water availability [21], and physical changes to the roots that can be esimated from two coaxial chamber model related to xylem and extensible tissues [22]. Hence, advanced understanding of plant behaviour is important for introduction of future precision systems. These would require extensive data that can only be obtained through laboratory experiments [23].

Despite the growing body of literature related to this area [24], this study will focus on commercial epiphytes. The plant species, commonly known as orchids, brings a considerable amount of revenue to countries such as Malaysia. Epiphytes have been included in the national conservation policies since 1992 [25], and continues until 2020 [26]. The vandaceous orchid is used for the study, in which changes to root diameters in response to water stress is recorded using dendrometer that is integrated with data logger system. The research gives useful insights into future water management system for orchid farms that utilize advanced system identification and modelling techniques. 


\section{RESEARCH METHODS}

\section{A. Consistency and Linearity Tests}

Dendrometer is a device used to measure various physical dimensions of plants. In this study, the DDS and DRO Root Aquatic Plant with DL 18 logger from Ecomatik is used to gauge the root diameter of an epiphyte. Two validation experiments are conducted on the devices. The procedures evaluate consistency of the dendrometer readings in relation to temperature and humidity changes. The latter are provided by HOBO U14 LCD External Temperature / Relative Humidity data logger. The first test is performed by setting up the dendrometer with no force applied to the expansion core. This configuration is maintained for a duration of 48 hours. Theoretically, there should not be any changes to the output as no force is being applied to the device.

Subsequently, a linearity test is performed by comparing changes to the dendrometer reading against the micrometer screw gauge. This is performed to verify specifications provided by the manufacturer. The test is performed twice for the range of $-3 \mathrm{~mm}$ to $+3 \mathrm{~mm}$. Positive and negative values are set by considering the value of $10 \mu \mathrm{m}$ on the micrometer as zero reference. The values of $7 \mathrm{~mm}$ and $13 \mathrm{~mm}$ on the micrometer represents $-3 \mathrm{~mm}$ and $+3 \mathrm{~mm}$, respectively. The ends of the micrometer spindle are fitted to the contracted dendrometer's expansion core. The readings for every $0.5 \mathrm{~mm}$ spindle movement on the dendrometer is recorded by a data logger.

Graphs are then plotted to observe for linearity error between dendrometer and the micrometer. The results are also observed for degree of consistency in dendrometer readings with temperature and humidity changes.

\section{B. Sampling and Data Collection}

The monopodial orchid that is used in this study is from genus Vanda, an epiphyte with huge stems. Two grown mericlones of Vanda hybrids, Ascocenda Fuchs Harvest Moon $\mathrm{x}$ (V. Chaophraya $\mathrm{x}$ Boots) is specifically selected to ensure that they have the same characteristics. The epiphytes are planted without any media, so that the root can only absorb water that is directly supplied to it. The studied samples are placed near to the open window to partially expose them to acceptable environment with at least $80 \%$ intensity from the sunlight.

The focus of the experiment to observe effect of water shortage on root diameter. Hence, both samples are not supplied with water, but rely on moisture from air. This induces water stress response. Theoretically, the roots will suffer from water shortage and causes its diameter to shrink. The dendrometers are attached to the active root of each sample. Data collection is performed from $3^{\text {rd }}$ to $17^{\text {th }}$ October 2018 using DRO Root Aquatic Plant with DL 18 logger. The root diameter, temperature, and humidity is logged at every 15 -minutes interval. Data logging time is synchronized between the two devices via HOBO interface that are installed on the computer.

Changes in the root diameter, temperature and humidity is then plotted against the time measured. Additional parameters sucha as maximum root diameter (MXRD), minimum root diameter (MNRD), maximum daily shrinkage (MDS), and daily shrinkage (DS) are then calculated based on the pattern of daily fluctuations in root diameter. DS and MDS can each be expressed by (1) and (2).

$$
\begin{aligned}
& \mathrm{MDS}=\operatorname{MXRD}_{\text {day } x}-\operatorname{MNRD}_{\text {day } x} \\
& \mathrm{DS}=\operatorname{MXRD}_{\text {day } x+1}-\operatorname{MXRD}_{\text {day } x}
\end{aligned}
$$

\section{RESULTS AND DISCUSSION}

Based on the validation experiments, the dendrometers are considered to be linear as the differences in measurement compared to micrometer screw gauge is only up to $0.02 \mu \mathrm{m}$. Fig. 1 illustrate the plot of micrometer displacement against DDS readings.

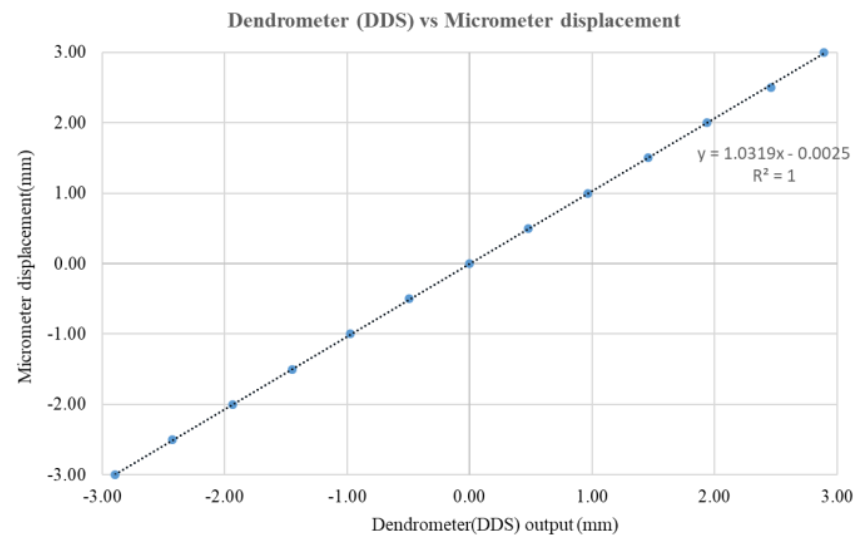

Fig. 1. Linearity and error between dendrometer (DDS) measurement and micrometer reading.

Meanwhile, the plot of micrometer displacement against DRO readings in Fig. 2 shows similar pattern with DDS.

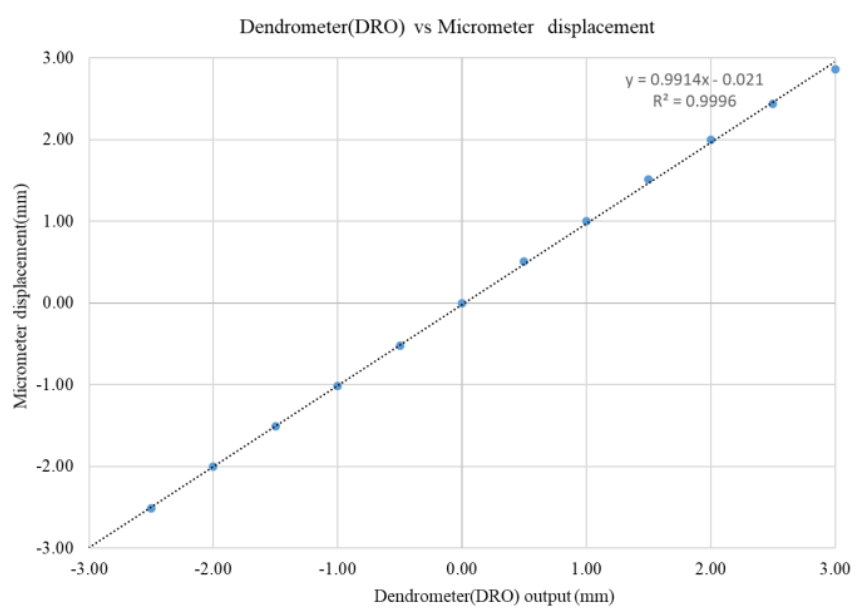

Fig. 2. Linearity and error between dendrometer (DRO) measurement and micrometer reading.

The dendrometers have also demonstrated high consistency with average reading of $3,195.6 \pm 0.132 \mu \mathrm{m}$ in varying levels of temperature and humidity. These are obtained over an average of 252 readings when its expansion core is contracted 
slightly to provide sufficient space, following the micrometer's spindle movement within the specified range. Results show that fluctuations of temperature and humidity have no effect on the dendrometer measurements. Such characteristics ensure that the root diameter will only change based on its water content. Following the linearity and consistency tests, dendrometers and other sensors are fixed to the samples as in Fig. 3. Meanwhile, Fig.4 shows the fluctuating parameters in the consistency tests.

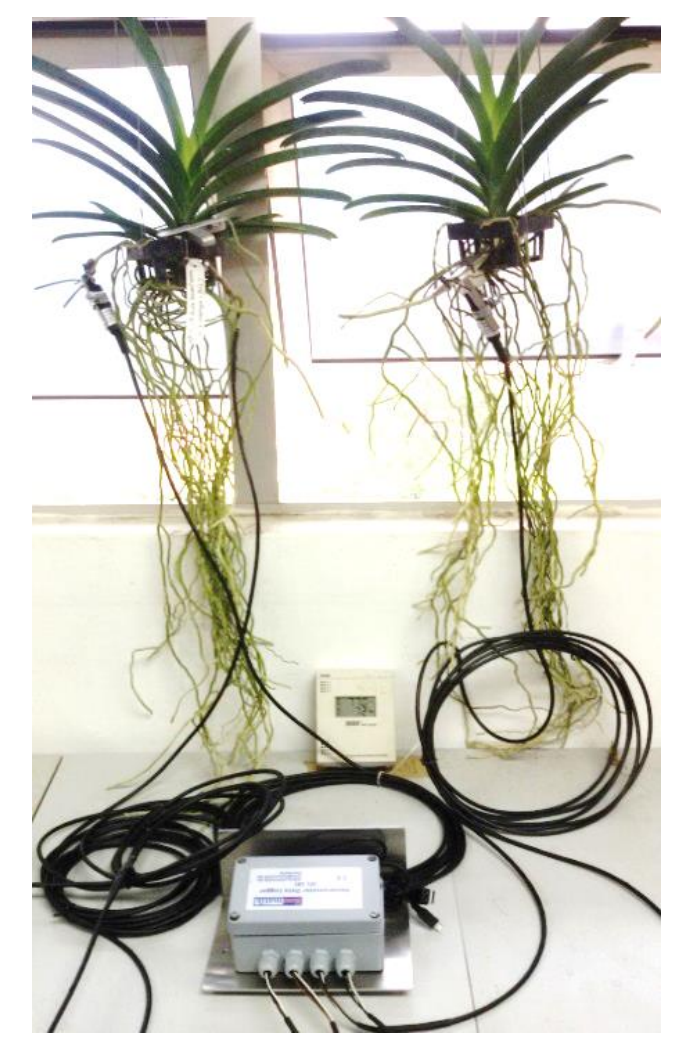

Fig. 3. The dendrometers secured to the vandaceous root structure, along with temperature and humidity sensors.

Fig. 5 illustrates the root diameter response for the entire study period of two weeks. The vertical axis represents change in root diameter $(\mu \mathrm{m})$. Meanwhile, the vertical axis on the right is shared by temperature $\left({ }^{\circ} \mathrm{F}\right)$ and humidity (\%). Generally, temperature fluctuations from day to day shows approximately similar pattern. However, the root diameter demonstrates a shrinking trend and these are evident from the decreasing daily maximum root diameter. Such phenomena is valid as no water is being supplied directly to the roots over the study period.

By focusing on the daily fluctuations, the greatest decrease in root diameter can be observed in the afternoon between 11.00 am to $1.00 \mathrm{pm}$. However, the root diameter will return back to its maximum plateau between $6.00 \mathrm{pm}$ to $1.00 \mathrm{am}$. These can be explained from the increasing humidity level at night. To better illustrate the daily fluctuating trends and its relationship with MXRD, MNRD, MDS, and DS, a magnified plot of root diameter changes from $3^{\text {rd }}$ to $5^{\text {th }}$ October 2018 is shown in Fig. 6 . The calculated MDS and DS is based on slightly modified method for estimating stem variation [24]. Table I shows the calculated parameters over the study period of two weeks.
TABLE I

DAILY CHANGE IN ROOT PARAMETERS

\begin{tabular}{cccccc}
\hline \hline Date & Day & $\begin{array}{c}\text { MXRD } \\
(\mu \mathrm{m})\end{array}$ & $\begin{array}{c}\text { MNRD } \\
(\mu \mathrm{m})\end{array}$ & $\begin{array}{c}\text { MDS } \\
(\mu \mathrm{m})\end{array}$ & $\begin{array}{c}\text { DS } \\
(\mu \mathrm{m})\end{array}$ \\
\hline $3 / 10 / 2018$ & 1 & $4,405.54$ & $4,316.09$ & 89.45 & 0 \\
$4 / 10 / 2018$ & 2 & $4,355.34$ & $4,302.14$ & 53.20 & -50.20 \\
$5 / 10 / 2018$ & 3 & $4,313.72$ & $4,250.09$ & 63.63 & -41.62 \\
$6 / 10 / 2018$ & 4 & $4,309.71$ & $4,274.29$ & 35.42 & -4.01 \\
$7 / 10 / 2018$ & 5 & $4,305.31$ & $4,282.17$ & 23.14 & -4.40 \\
$8 / 10 / 2018$ & 6 & $4,294.58$ & $4,237.51$ & 57.07 & -10.73 \\
$9 / 10 / 2018$ & 7 & $4,238.70$ & $4,202.26$ & 36.44 & -55.88 \\
$10 / 10 / 2018$ & 8 & $4,211.33$ & $4,175.60$ & 35.73 & -27.37 \\
$11 / 10 / 2018$ & 9 & $4,189.02$ & $4,176.61$ & 12.41 & -23.31 \\
$12 / 10 / 2018$ & 10 & $4,188.84$ & $4,180.44$ & 8.40 & -0.81 \\
$13 / 10 / 2018$ & 11 & $4,183.30$ & $4,175.42$ & 7.88 & -5.54 \\
$14 / 10 / 2018$ & 12 & $4,175.60$ & $4,173.93$ & 1.67 & -7.70 \\
$15 / 10 / 2018$ & 13 & $4,174.60$ & $4,173.58$ & 0.83 & -1.00 \\
$16 / 10 / 2018$ & 14 & $4,174.59$ & $4,154.44$ & 20.05 & -0.01 \\
$17 / 10 / 2018$ & 15 & $4,154.92$ & $4,110.61$ & 44.31 & -19.67 \\
\hline \hline
\end{tabular}

Generally, data on root diameter changes gives an indication on whether adequate water is being supplied to the plants daily. The MXRD and MNRD parameters are actual values recorded by the dendrometers. As previously elaborated, both parameters are then used to derive MDS and DS. The negative values of DS indicates the the roots diameter steadily decreases, implying that the epiphytes is without water supply for more than a day.

\section{CONCLUSION}

The study has shown the potential use of dendrometers for continuous monitoring of water status in epiphytes. Results indicate that the sensors can be integrated in decision support systems for automated irrigation in commercial orchid farms. This would have significant impact as the watering practices for epiphytes are different from terrestrial plants. Based on this study, the change of root diameter has demonstrated the best correlation with water status of the plant and thus, has the potential to be used as reference to initiate watering procedure.

In the experimental setup, samples were forced to naturally acquire water without any form of assistance. Similar behaviour in epiphytes have been observed compared to terrestrial plants where root diameter will decrease without water supply. The rate of reduction however, is dependent on other factors such as microclimate of the surrounding environment, change of study protocols, and the species used as sample.

Further study is needed to observe root diameter changes based on other factors such as climate, watering practices, and effects of fertilization for improved growth profile. This will help in determining the thresholds; not only for avoiding water shortage, but excessive watering to the epiphytes. Also, studies can also be conducted to observe stem response to water stress, as well as correlation between root and stem responses. 
Dendrometer consistency Vs Temperature and Relative Humidity

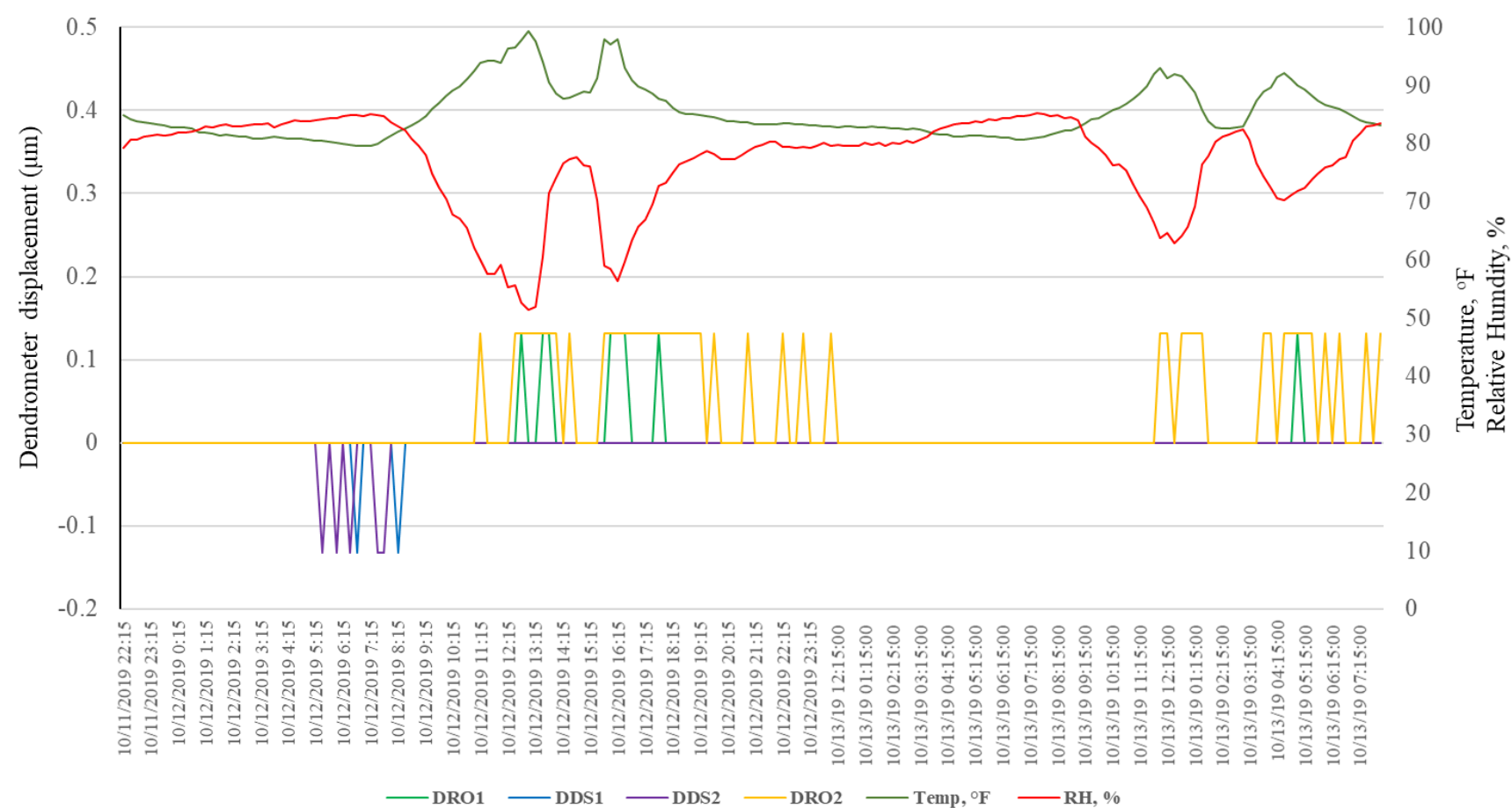

Fig. 4. Consistency of dendrometer measurements with temperature and humidity changes.

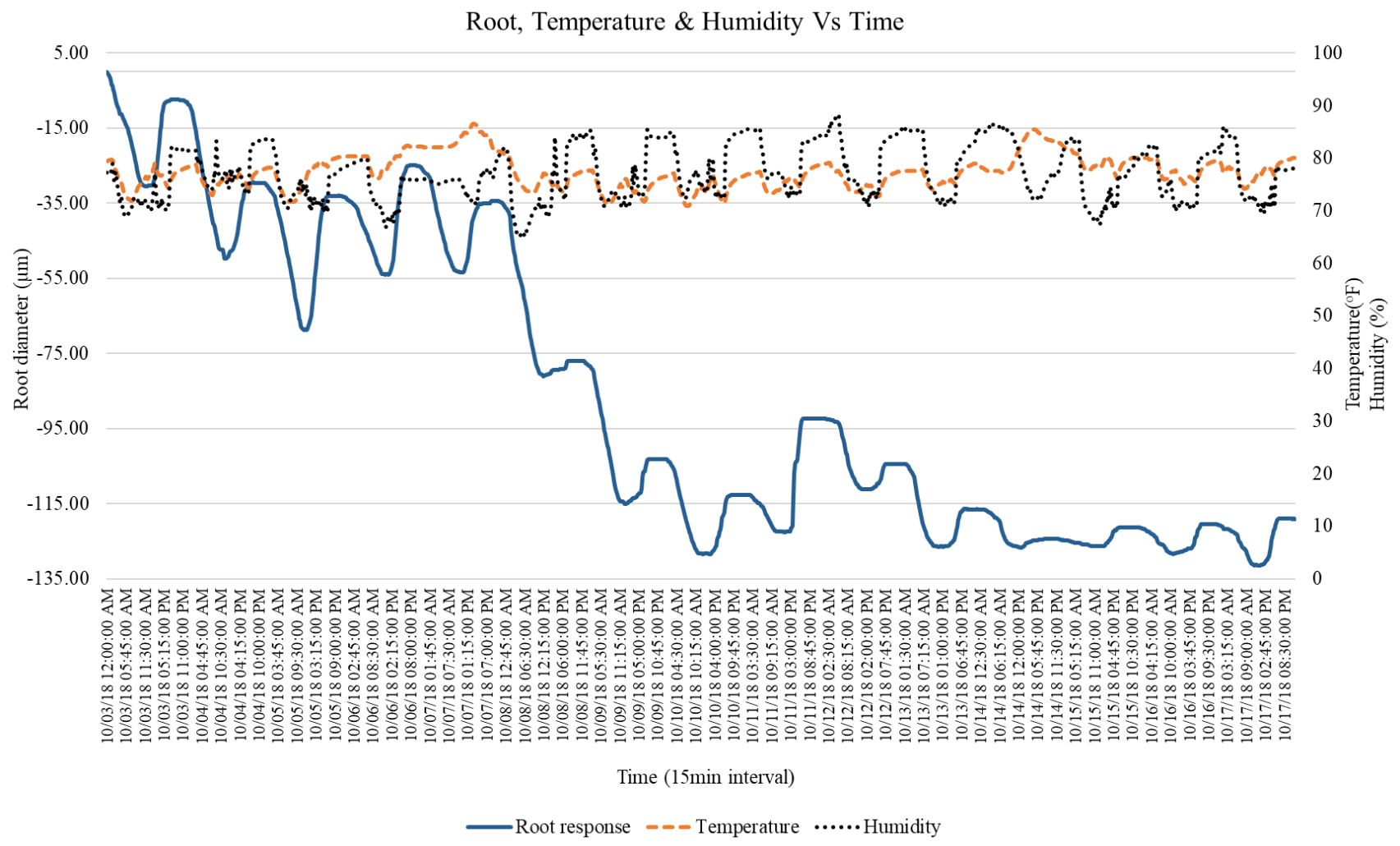

Fig. 5. Daily variations in root diameter, temperature and humidity. 


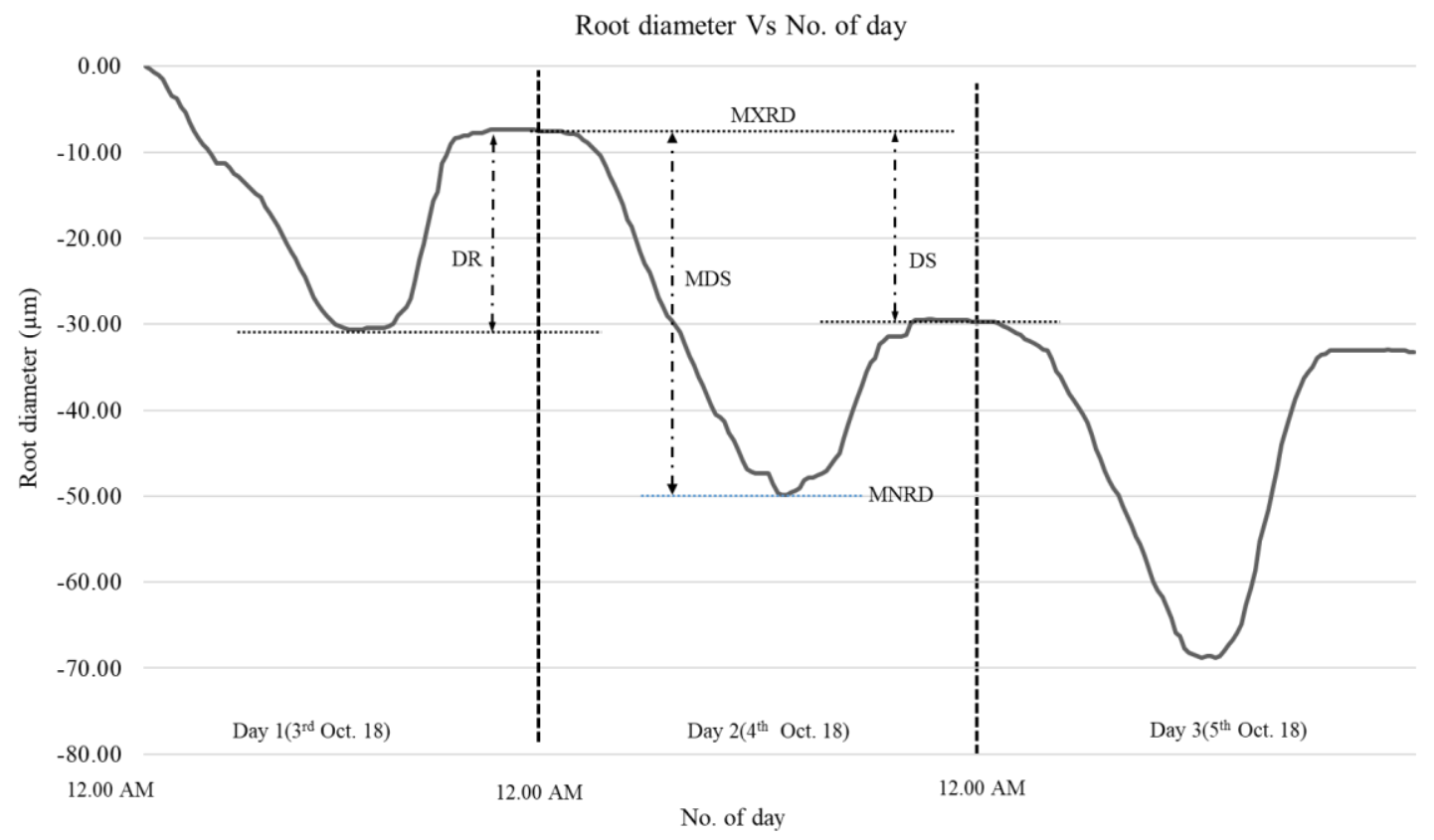

Fig. 6. Daily MXRD, MNRD, MDS and DS parameters.

\section{REFERENCES}

[1] A. Bonfante, E. Monaco, P. Manna, R. De Mascellis, A. Basile, M. Buonanno, G. Cantilena, A. Esposito, A. Tedeschi, C. De Michele, O. Belfiore, I. Catapano, G. Ludeno, K. Salinas, and A. Brook, "LCIS DSSAn irrigation supporting system for water use efficiency improvement in precision agriculture: A maize case study," Agricultural Systems, vol. 176, p. 102646, 2019.

[2] M. H. Egerer, B. B. Lin, C. G. Threlfall, and D. Kendal, "Temperature variability influences urban garden plant richness and gardener water use behavior, but not planting decisions," Science of The Total Environment, vol. 646, pp. 111-120, 2019.

[3] S. Higgins, J. Schellberg, and J. S. Bailey, "Improving productivity and increasing the efficiency of soil nutrient management on grassland farms in the UK and Ireland using precision agriculture technology," European Journal of Agronomy, vol. 106, pp. 67-74, 2019.

[4] W. Elmer, C. Ma, and J. White, "Nanoparticles for plant disease management," Current Opinion in Environmental Science \& Health, vol. 6, pp. 66-70, 2018.

[5] G. Aiello, M. Vallone, and P. Catania, "Optimising the efficiency of olive harvesting considering operator safety," Biosystems Engineering, vol. 185, pp. 15-24, 2019.

[6] Y. Ma, "Seed coating with beneficial microorganisms for precision agriculture," Biotechnology Advances, vol. 37, no 7, p. 107423, 2019.

[7] R. Morais, N. Silva, J. Mendes, T. Adão, L. Pádua, J. A. López-Riquelme, N. Pavon-Pulido, J. J. Sousa, and E. Peres, "mySense: A comprehensive data management environment to improve precision agriculture practices," Computers and Electronics in Agriculture, vol. 162, pp. 882894, 2019.

[8] G. I. Ezenne, L. Jupp, S. K. Mantel, and J. L. Tanner, "Current and potential capabilities of UAS for crop water productivity in precision agriculture," Agricultural Water Management, vol. 218, pp. 158-164, 2019.

[9] G. Vellidis, M. Tucker, C. Perry, C. Kvien, and C. Bednarz, "A real-time wireless smart sensor array for scheduling irrigation," Computers and Electronics in Agriculture, vol. 61, no. 1, pp. 44-50, 2008.

[10] H. G. Jones, "Monitoring plant and soil water status: Established and novel methods revisited and their relevance to studies of drought tolerance," Journal of Experimental Botany, vol. 58, no. 2, pp. 119-130, 2007.

[11] S. Sevanto, T. N. Mikkelsen, K. Pilegaard, and T. Vesala, "Comparison of tree stem diameter variations in beech (Fagus sylvatica L.) in Sorø
Denmark and in Scots pine (Pinus sylvestris L.) in Hyytiälä, Finland," Boreal Environment Research, vol. 8, pp. 457-464, 2003.

[12] T. De Swaef, K. Steppe, and R. Lemeur, "Determining reference values for stem water potential and maximum daily trunk shrinkage in young apple trees based on plant responses to water deficit," Agricultural Water Management, vol. 96, no. 4, pp. 541-550, 2009.

[13] S. Fabre, A. Lesaignoux, A. Olioso, and X. Briottet, "Influence of water content on spectral reflectance of leaves in the 3-15 domain," IEEE Geoscience and Remote Sensing Letters, vol. 8, no. 1, pp. 143-147, 2011.

[14] K. -E. Lee, J. -W. Kim, C. -Y. Kim, and S. -H. Ahn, "Development of micro torque measurement device using strain gauge," in 2009 IEEE International Symposium on Assembly and Manufacturing, Suwon, 2009, pp. 101-106.

[15] B. Dichio, G. Margiotta, C. Xiloyannis, S. A. Bufo, A. Sofo, and T. R. I. Cataldi, "Changes in water status and osmolyte contents in leaves and roots of olive plants (Olea europaea L.) subjected to water deficit," Trees, vol. 23, pp. 247-256, 2009.

[16] D. M. Drew, A. P. O'Grady, G. M. Downes, J. Read, and D. Worledge, "Daily patterns of stem size variation in irrigated and unirrigated Eucalyptus globulus," Tree Physiology, vol. 28, no. 10, pp. 1573-1581, 2008.

[17] W. Wang, H. Ming, J. Yang, and R. Zong, "Precise diagnosis of water stress in plants based on microwave sensor," in 2006 IEEE International Conference on Information Acquisition, Weihai, 2006, pp. 1163-1167.

[18] T. A. Sousa, M. T. Oliveira, and J. M. Pereira, "Physiological indicators of plant water status of irrigated and non-irrigated grapevines grown in a low rainfall area of Portugal," Plant and Soil, vol. 282, pp. 127-134, 2006.

[19] D. M. Drew and G. M. Downes, "The use of precision dendrometers in research on daily stem size and wood property variation: A review," Dendrochronologia, vol. 27, no. 2, pp. 159-172, 2009.

[20] D. M. Qiao, H. B. Shi, H. B. Pang, X. B. Qi, and F. Plauborg, "Estimating plant root water uptake using a neural network approach," Agricultural Water Management, vol. 98, no. 2, pp. 251-260, 2010.

[21] Y. Bao, P. Aggarwal, N. E. Robbins II, C. J. Sturrock, M. C. Thompson, H. Q. Tan, C. Tham, L. Duan, P. L. Rodriguez, T. Vernoux, S. J. Mooney, M. J. Bennett, and J. R. Dinneny, "Plant roots use a patterning mechanism to position lateral root branches toward available water," Proceedings of the National Academy of Sciences, vol. 111, no. 25, pp. 9319-9324, 2014.

[22] M. Génard, S. Fishman, G. Vercambre, J. -G. Huguet, C. Bussi, J. Besset, and R. Habib, "A biophysical analysis of stem and root diameter variations in woody plants," Plant Physiology, vol. 126, no. 1, pp. 188202, 2001.

[23] R. Dong, Y. Li, W. Li, H. Zhang, Y. Liu, L. Ma, X. Wang, and B. Lei, "Recent developments in luminescent nanoparticles for plant imaging and 
photosynthesis," Journal of Rare Earths, vol. 37, no. 9, pp. 903-915, 2019.

[24] J. E. Fernández and M. V. Cuevas, "Irrigation scheduling from stem diameter variations: A review," Agricultural and Forest Meteorology, vol. 150, no. 2, pp. 135-151, 2010.

[25] Tanaman Orkid Komersial Untuk Bunga Keratan, Jabatan Pertanian Semenanjung Malaysia, Kuala Lumpur, 1998.

[26] Dasar Agro Makanan Negara 2011-2020, Kementerian Pertanian dan Industri Asas Tani Malaysia, Putrajaya, 2011.

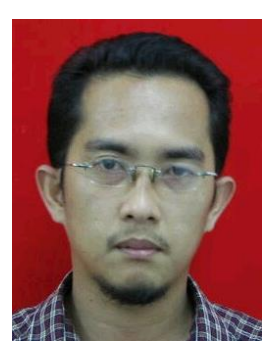

Mohd Khairi Nordin received his Dip. in Electromechanical Engineering from Politeknik Ungku Omar, Malaysia, B.Eng. (Electrical), and M.Sc. in Electrical Engineering from Universiti Teknologi MARA, Malaysia. He is a lecturer at the Faculty of Electrical Engineering, Universiti Teknologi MARA. His research interests are in sensors and instrumentation, precision agriculture, and system identification. Mr. Khairi is currently pursuing his Ph.D. at the Faculty of Electrical Engineering, Universiti Teknologi MARA.

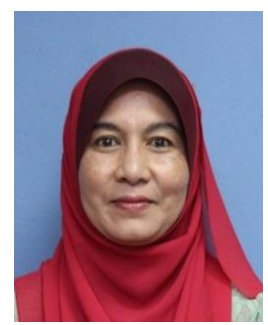

Nooritawati Md Tahir received her B.Eng (Electronics) from the Universiti Teknologi MARA, Malaysia, M.Sc. (Microelectronics \& Telecommunications) from University of Liverpool, United Kingdom, and Ph.D. in Electrical Engineering (Pattern Recognition \& Artificial Intelligence) from Universiti Kebangsaan Malaysia, Malaysia. She is currently a Professor at the Faculty of Electrical Engineering and Director of Research Nexus UiTM, Universiti Teknologi MARA. Her research interests include image processing, pattern recognition, computer vision and artificial intelligence.

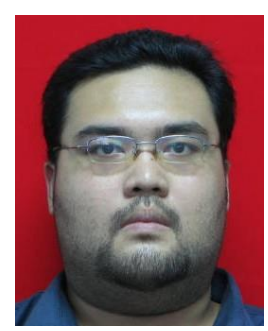

Ahmad Ihsan Mohd Yassin received his B.Sc. in Electrical Engineering from Universiti Tun Hussein Onn, Malaysia, M.Sc. as well as Ph.D. in Electrical Engineering from Universiti Teknologi MARA, Malaysia. Dr. Ihsan is currently an Associate Professor at the Faculty of Electrical Engineering, Universiti Teknologi MARA. His research interests are in deep learning, blockchain technology, optimization, and system identification. Dr. Ihsan is currently a research fellow at the Microwave Research Institute, Universiti Teknologi MARA.

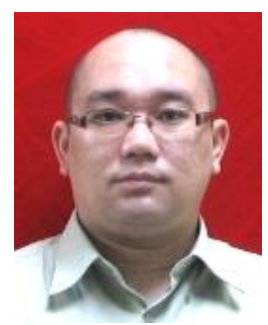

Megat Syahirul Amin Megat Ali received his B.Eng. (Biomedical) from University of Malaya, Malaysia, M.Sc. in Biomedical Engineering from University of Surrey, United Kingdom, and Ph.D. in Electrical Engineering from Universiti Teknologi MARA, Malaysia. He is a senior lecturer at the Faculty of Electrical Engineering, Universiti Teknologi MARA. His research interests include biomedical signal processing and artificial intelligence. Dr. Megat is currently a research fellow at the Microwave Research Institute, Universiti Teknologi MARA. 